\title{
A rare presentation of deep infiltrating cervical endometriosis mimicking cervical cancer
}

\author{
Swetha P.*, Nagashree U., Kondammal R.
}

Department of Obstetrics and Gynaecology, Apollo Women's Hospital, Chennai, Tamil Nadu, India

Received: 17 July 2020

Accepted: 08 August 2020

\section{* Correspondence:}

Dr. Swetha P.,

E-mail: swetha14july@yahoo.co.in

Copyright: (C) the author(s), publisher and licensee Medip Academy. This is an open-access article distributed under the terms of the Creative Commons Attribution Non-Commercial License, which permits unrestricted non-commercial use, distribution, and reproduction in any medium, provided the original work is properly cited.

\begin{abstract}
Though endometriosis is a common progressive benign disorder of women, endometriosis of the cervix is rarely seen. It poses a challenge both for diagnosis and management. Most of the patients with Cervical endometriosis are asymptomatic, present with abnormal vaginal bleeding, post-coital bleeding or intermenstrual bleeding. In this paper, we report a rare case of deep infiltrating cervical endometriosis involving the ureter mimicking cervical cancer, the need for awareness to include cervical endometriosis as a differential diagnosis in case of menstural irregularities and its potential to cause serious complications.
\end{abstract}

Keywords: Cervical endometriosis, Colposcopy, Hydroureteronephrosis

\section{INTRODUCTION}

The prevalence is about $2.4 \%$ and the diagnosis is most often retrospective based on the histological report ${ }^{1,2}$ Cervical endometriosis is defined as the presence of endometrial glands or stroma at the cervical level. Primary and secondary cervical endometriosis has been explained wherein primary cervical endometriosis is defined as ectopic endometrial tissue at the level of the cervix is a rare entity. ${ }^{3}$ Criteria for primary endometriosis was established by Siddal and Mack. ${ }^{4,5}$ Secondary cervical endometriosis is more commonly seen than the primary type is due to the extension of the disease from the pelvis, usually from the rectovaginal septum.

Various theories have been postulated to explain the cause of cervical endometriosis but no single theory can explain in all cases and hence interplay of combined factors explained by more than one proposed theory play a role in the development of cervical endometriosis. ${ }^{6}$

It is a benign condition which is asymptomatic most of the times but may present with symptoms like post-coital bleed, intermenstrual spotting. Colposcopy, cervical biopsy and Fine Needle Aspiration Cytology (FNAC) are important investigations for superficial endometriosis as only a histopathological report can confirm the diagnosis and further management can be planned. Surgical treatment is the best choice for deep endometriosis to relieve the patient of her symptoms and reduce the morbidity.

\section{CASE REPORT}

A 45-year-old woman referred from the urology department with complaints of persistent lower abdominal pain and right-sided flank pain from 6 to 7 months. She also gives a history of intermenstrual bleeding for one year. She had one full term normal vaginal delivery. She is hypertensive on treatment. On per-vaginal examination, right fornix was pulled up and an irregular nodular mass was felt in the right fornix. Pap smear showed inflammatory smear, no malignant cells.

She underwent computed tomography (CT) scan and Magnetic Resonance Imaging (MRI) of the abdomen which showed a large ill-defined T2W hyperintense lesion involving the uterine cervix. The mass was seen 
compressing the right distal ureter with grade III hydronephrosis on the right side. The report stated a heterogeneously hypo intense ill-defined lesion with mild diffusion restriction and intense enhancement involving posterior and right lateral wall of cervix, extending into the lower uterine segment and right parametrial region the possibility of neoplastic etiology likely. Right moderate hydroureteronephrosis with abrupt tapering at distal ureter at the right parametrial region. Well defined hypointense lesion with diffusion restriction in the anterior wall of the lower uterine segment- likely high cervical fibroid. Few nabothian cysts in the cervix seen. DMSA renal scan showed faintly visualised right kidney with no significant cortical function with the renal function of $2 \%$. Left kidney showed no cortical scarring with the renal function of $98 \%$. A transvaginal ultrasound suggested of posterior cervical mass with extension into the lower segment of the uterus. Other routine blood investigations were found to be normal.

Given the high suspicion for cervical cancer and severe right hydronephrosis affecting the right renal function, the patient was taken up for surgery. Cystoscopy and right ureteric stenting were done before proceeding with a total abdominal hysterectomy and bilateral salphingooophorectomy.

The intraoperative findings were: uterus, tubes and ovaries were normal. There was endocervical induration with hardening of the parametrium and involvement of right Mackenrodt's ligaments and lower part of the uterus on the right side. Bowel adhesions to the right lower part of uterus present. Left parametrium normal.

Post-operative period was uneventful and she was discharged on the third postoperative day with the stent in-situ. She was reviewed after a month and stent removal was done, her renal function was reassessed which showed a marked improvement and hence nephrectomy was deferred. The histopathological report showed endometriosis of cervix, secondary endometrium with myometrium being unremarkable.

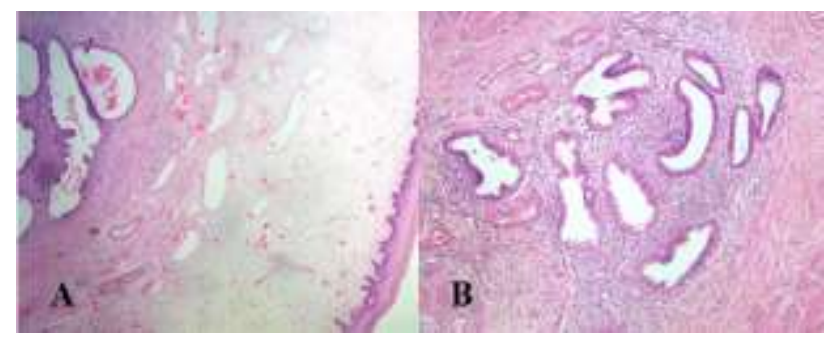

Figure 1 (A and B): Depicts presence of endometrium in the cervical tissue.

\section{DISCUSSION}

Cervical endometriosis is seen very rarely much lesser than even the extra pelvic sites like an abdominal wall or vaginal wall. ${ }^{6}$ The theories that can explain endometriosis are Sampson's menstrual reflex and implantation theory. ${ }^{7}$ most of the literature suggested Cervical trauma in relation to cervical endometriosis. ${ }^{2,8}$ The possibility that cervical endometriosis develops in Mullerian rests which persists in the stroma of cervix was suggested by Hoang et al. ${ }^{9}$ The intrinsic character of eutopic endometrium determining the capability of the growth of ectopic endometriotic tissue has also been a popular theory. ${ }^{10,11}$ Further progression of the disease depends on high estrogen levels. In this patient there is no history of any cervical surgery or procedure like dilatation and curettage, biopsy ruling out any cervical trauma and hence the most likely theory for her developing cervical endometriosis could be explained by the abnormal intrinsic properties of eutopic endometrium, embryonic remnants and metaplastic origination.

Cervical endometriosis may be superficial or deep. Superficial endometriosis involves epithelium adjacent to cervical stroma whereas deep cervical endometriosis involves the outer third of the cervical wall, rectovaginal septum or serosal surface of the supravaginal portion of the cervix. In this case, the microscopic description given in the histopathology report stated that the cervical tissue showed few dilated endocervical glands and focal papillary endocervical proliferation and subserosal lymphomononuclear cell infiltration along with congestion. There are foci of endometrial type of glands along with stroma with evidence of haemorrhage. Sections from the isthmic tissue also showed the presence of benign endometrial glands along with stroma.

In our case, there was no abnormality in the pap smear but many times it can show glandular abnormalities like cervicitis, endocervical gland dysplasia, adenocarcinoma in situ, squamous carcinoma in situ, atypical squamous metaplasia involving glands and tubal metaplasia especially in the superficial cervical endometriosis. Cervical endometriosis being a source of atypical glandular cells should be kept in mind. ${ }^{12-15}$ Diagnosis can be improved by colposcopic biopsy or FNAC. Other differential diagnosis includes cervical fibroids, endocervical polyp, sub mucous leiomyoma or cancerous lesions.

Most of the patients are asymptomatic and can be managed expectantly. Medical treatment such as oral contraceptive pills and gonadotropin-releasing hormone analogues can be offered to patients with mild symptoms. ${ }^{16}$ Surgical management is reserved for patients with persistant symptoms. Conservative surgeries like excision, LLETZ, electrocoagulation, cryotherapy can be an option for small localized superficial endometriosis. Surgical management creating further trauma and potential of reimplantation and recurrence was postulated, but work of Wang et al has shown that no recurrence was seen commonly. ${ }^{6}$ Total Hysterectomy is a definitive treatment for patients with deep cervical endometriosis and when malignancy cannot be excluded. ${ }^{17}$ Due to the likeliness of cervical cancer and a 
significant reduction in right kidney function due to the right ureteric involvement in our case the patient was taken up for right ureteric stenting and total abdominal hysterectomy. Extensive endometriosis with colorectal involvement requires multidisciplinary approach, proper counselling regarding progression of the disease, importance of follow up to avoid vital organ injury as in our case needs to be kept in mind.

\section{CONCLUSION}

Cervical endometriosis is a rare benign lesionand it shares its characteristics with more common conditions and hence poses a challenge in diagnosis. An abnormal pap smear should be followed by a colposcopic guided biopsy or FNAC to give a better insight of diagnosis and can be helpful particularly in the superficial cervical endometriosis. Deep cervical endometriosis has to be evaluated properly and it needs serial follow up to study the course of disease. It can be managed surgically by total hysterectomy. In our case, the surgical management by total abdominal hysterectomy has completely relieved the patient of her symptoms and shown a significant improvement in the right renal function thereby avoiding nephrectomy. A multidisciplinary approach for these patients is required for the best possible outcome.

Funding: No funding sources

Conflict of interest: None declared

Ethical approval: Not required

\section{REFERENCES}

1. Veiga-Ferreira MM, Leiman G, Dunbar F, Margolius KA. Cervical endometriosis: facilitated diagnosis by fine needle aspiration cytologic testing. Am J Obstet Gynecol. 1987;157:849-56.

2. Phadnis SV, Doshi JS, Ogunnaike O, Coady A, Padwick M, Sanusi FA. Cervical endometriosis: a diagnostic and management dilemma. Arch Gynecol Obstet. 2005;272:289-93.

3. Cramer, Daniel W, Missmer SA. Epidemiology of endometriosis. Endometriosis in Clinical Practice. CRC Press. 2004;79-94.

4. Siddall RS, Mack HC. Primary endometriosis of the cervix uteri. Harper Hosp Bull. 1949;7:195.

5. Siddall RS, Mack HC. Primary endometriosis of the vagina; portion of the cervix uteri. Am J Obst And Gynec. 1949;60:765.

6. Wang S, Li XC, Lang JH. Cervical endometriosis: clinical character and management experience in a 27-year span. Am J Obstet Gynecol. 2011;205:e1-5.
7. Sampson JA. The development of the implantation theory for the origin of peritoneal endometriosis. Am J Obstet Gynecol. 1940;40:549-55.

8. Baker PM, Clement PB, Bell DA, Young RH. Superficial endometriosis of the uterine cervix: a report of 20 cases of a process that may be confused with endocervical glandular dysplasia or adenocarcinoma in situ. Int $\mathbf{J}$ Gynecol Pathol. 1999;18:198-205.

9. Hoang NM, Smadja A, Orcel L. Endometriosis of the uterine cervix. A hypothesis on its histogenesis. J Gynecol Obstet Biol Reprod. 1987;16(5):587-93.

10. Vinatier D, Orazi G, Cosson M, Dufour P. Theories of endometriosis. Eur J Obstet Gynecol Reprod Biol. 2001;96:21-34.

11. Sharpe-Timms KL. Defining endometrial cells: the need for improved identification at ectopic sites and characterization in eutopic sites for developing novel methods of management for endometriosis. Fertil Steril. 2005;84:35-9.

12. Symonds DA, Reed TP, Didolkar SM, Graham RR. AGUS in cervical endometriosis. J Reprod Med. 1997;42(1):39-43.

13. Kim TJ, Kim HS, Park CT, Park IS, Hong SR, Park JS, et al. Clinical evaluation of follow-up methods and results of atypical glandular cells of undetermined significance (AGUS) detected on cervicovaginal Pap smear. Gynecol Oncol. 1999;73 (2):292-8.

14. Lundeen SJ, Horwitz CA, Larson CJ, Stanley MW. Abnormal cervicovaginal smears due to endometriosis: a continuing problem. Diagn Cytopathol. 2002;26(1):35-40.

15. Szyfelbein WM, Baker PM, Bell DA. Superficial endometriosis of the cervix: A source of abnormal glandular cells on cervicovaginal smears. Diagn Cytopathol. 2004;30(2):88-91.

16. Kano H, Kanda H. Cervical endometriosis presented as a polypoid mass of portio cervix uteri. J Obstet Gynaecol. 2003;23:84-5.

17. Vercellini P, De Giorgi O, Pisacreta A, Vicentini S, Crosignani PG. Surgical management of endometriosis. Ballieres Best Pract Res Clin Obstet Gynaecol 2000;14:501-23.

Cite this article as: Swetha $P$, Nagashree U, Kondammal R. A rare presentation of deep infiltrating cervical endometriosis mimicking cervical cancer. Int J Reprod Contracept Obstet Gynecol 2020;9:3903-5. 